\title{
Physical activity, bone metabolism and inflammatory markers, and bone mineral density in elderly men: a preliminary investigation
}

Elisa A Marques ${ }^{1}$, Jorge Mota1 ${ }^{1}$ João L Viana ${ }^{2,3}$, Pedro Figueiredo², U.PORTO João T Guimarães ${ }^{4,5}$, and Joana Carvalho ${ }^{1}$

${ }^{1}$ CIAFEL, Faculty of Sport Science, University of Porto, Porto, Portugal.

2 Higher Education Institute of Maia (ISMAI), Maia, Portugal

${ }^{3}$ Research Center in Sports, Health Sciences and Human Development (CIDESD), Portugal.

${ }^{4}$ Department of Clinical Pathology, S. João Hospital, Porto, Portugal.

${ }^{5}$ Department of Biochemistry, Faculty of Medicine, University of Porto, Porto, Portugal.

e-mail: emarques@fade.up.pt

\section{Introduction}

Most studies to date have focus on the effect of exercise interventions on bone remodeling. Furthermore, inflammation has been associated with those critical for bone physiology and remodeling. However, investigations analyzing the relationship between objective physical activity and bone metabolism and inflammatory markers and the potential interactions with BMD and body composition in older men are limited, which is the aim of the present cross-sectional study (approved by local Ethical Committee).

\section{Methods}
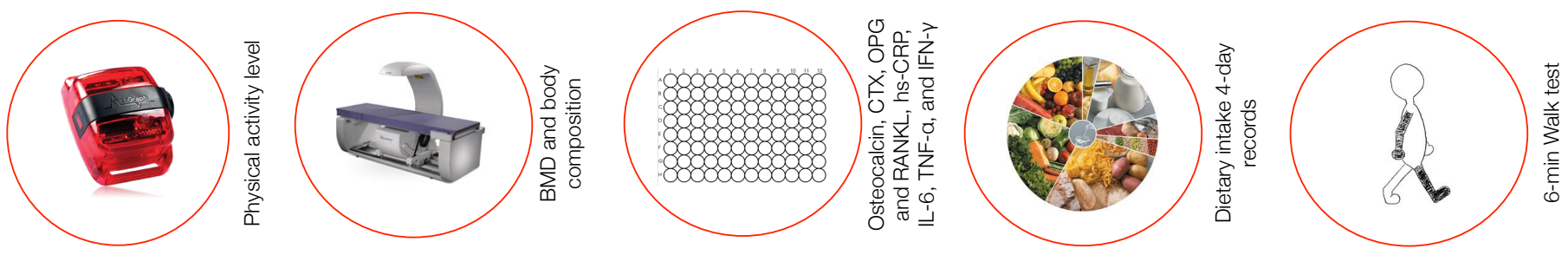

\section{Comparing two means: Results}

Table 1 - Means, standard-deviation and P-value of outcome variables for both physical activity level groups

\begin{tabular}{lccc}
\hline Variable & LPA Group $(\mathrm{n}=17)$ & HPA Group $(\mathrm{n}=18)$ & P-value \\
\hline Age (years) & $71.0 \pm 5.46$ & $67.58 \pm 5.38$ & 0.146 \\
6-min walk test $(\mathrm{m})$ & $562.73 \pm 66.61$ & $649.17 \pm 61.31$ & 0.004 \\
Fat mass $(\%)$ & $29.93 \pm 4.49$ & $25.45 \pm 5.06$ & 0.036 \\
Lumbar Spine $\left(\mathrm{g} / \mathrm{cm}^{2}\right)$ & $1.05 \pm 0.16$ & $1.05 \pm 0.17$ & 0.930 \\
Femoral Neck $\left(\mathrm{g} / \mathrm{cm}^{2}\right)$ & $0.82 \pm 0.11$ & $0.82 \pm 0.12$ & 0.975 \\
OC $(\mathrm{ng} / \mathrm{mL})$ & $14.85 \pm 1.55$ & $13.38 \pm 3.63$ & 0.218 \\
CTX $(\mathrm{ng} / \mathrm{mL})$ & $0.39 \pm 0.11$ & $0.36 \pm 0.13$ & 0.496 \\
OPG $(\mathrm{pg} / \mathrm{mL})$ & $481.62 \pm 124.75$ & $388.04 \pm 114.40$ & 0.075 \\
RANKL $(\mathrm{pg} / \mathrm{mL})$ & $32.46 \pm 6.19$ & $22.38 \pm 10.05$ & 0.009 \\
IL-6 $(\mathrm{pg} / \mathrm{mL})$ & $2.21 \pm 1.15$ & $1.09 \pm 1.12$ & 0.027 \\
TNF- $\alpha(\mathrm{pg} / \mathrm{mL})$ & $8.13 \pm 2.08$ & $6.70 \pm 1.84$ & 0.097 \\
IFN- $\gamma(\mathrm{pg} / \mathrm{mL})$ & $0.85 \pm 0.47$ & $0.43 \pm 0.25$ & 0.018 \\
Hs-CRP $(\mathrm{mg} / \mathrm{L})$ & $3.69 \pm 2.09$ & $1.46 \pm 0.99$ & 0.003 \\
\hline
\end{tabular}

\section{Correlation: Results}

MVPA and aerobic capacity were not correlated with BMD. There was a significant inverse correlation between MVPA and hs-CRP ( $r=-0.424$, $\mathrm{P}=.04)$, RANKL ( $r=-0.506, \mathrm{P}=.014)$, and IL-6 ( $r=-.433, \mathrm{P}=.038)$. Aerobic capacity was also negatively correlated with hs-CRP. Unexpected, OPG was negatively correlated with MVPA $(r=-0.463, P=.026)$ and aerobic capacity ( $r=-0.451, P=.031)$.

\section{Conclusions}

These data provide preliminary evidence that daily MVPA may induce suppression of hs-CRP, RANKL and IL-6. Additional studies with larger sample sizes will be needed to explore the association between MVPA and OPG and to determine the potential mechanism by which exercise may correlate negatively with OPG-RANKL-RANKL system. 